\title{
Kualitas Kehidupan Kerja pada Wanita Pekerja: Studi pada Pekerja Wanita di Lingkup Bank BRI Syariah Cabang Semarang
}

\author{
Zuhdan Ady Fataron \\ Universitas Islam Negeri Walisongo Semarang \\ email: zuhdan@walisongo.co.id
}

\begin{abstract}
The double burden on women's work as schedules and work demands can make it difficult for women to fulfill family demands to have an unfavorable impact on both their working lives and on family life. It is necessary for a positive work-family interaction built through spiritual intelligence and work engagement. The focus of this study is to examine the effect of spiritual intelligence and work engagement in explaining the positive work-family interaction in order to build quality work life. Research data related to these variables obtained through interviews using questionnaires answered by the respondents working women, have a family and have children. The data obtained were analyzed by Structural Equation Modeling (SEM) approach. The results of data analysis showed that spiritual intelligence and work engagement were statistically proved to have a significant positive effect on family-positive work interaction. Similarly, a positive work-family interaction is evidently able to explain the quality of work life.
\end{abstract}

Keywords: spiritual intelligence; work engagement; positive work-family interaction; quality of work life.

Abstrak: Beban ganda pada pekerjaan perempuan seperti jadwal dan tuntutan kerja dapat menyulitkan perempuan untuk memenuhi tuntutan keluarga, memiliki dampak yang tidak menguntungkan baik pada kehidupan kerja maupun kehidupan keluarga mereka. Hal ini memerlukan adanya interaksi positif pekerjaan-keluarga yang dibangun melalui kecerdasan spiritual dan work engagement. Fokus dari penelitian ini adalah untuk menguji pengaruh kecerdasan spiritual dan work engagement dalam menjelaskan interaksi positif keluarga-kerja untuk membangun kehidupan kerja yang berkualitas. Data penelitian yang berkaitan dengan variabel-variabel ini diperoleh melalui wawancara dengan menggunakan kuesioner yang dijawab oleh responden wanita pekerja, memiliki keluarga dan memiliki anak. Data yang diperoleh dianalisis dengan pendekatan Structural Equation Modeling (SEM). Hasil analisis data menunjukkan bahwa kecerdasan spiritual dan work engagement secara statistik terbukti memiliki efek positif yang signifikan terhadap interaksi positif pekerjaan-keluarga. Demikian pula, interaksi positif pekerjaan-keluarga ternyata mampu menjelaskan kualitas kehidupan kerja.

Kata Kunci: kecerdasan spiritual; keterikatan pekerjaan; interaksi positif pekerjaan-keluarga; kualitas kehidupan kerja.

Economica: Jurnal Ekonomi Islam - Volume 8, Nomor 2 (2017) 


\section{Pendahuluan}

Isu terjunnya perempuan ke dalam dunia kerja sangat menarik untuk dikaji. Hal ini terkait dengan bagaimana pemahaman masyarakat mengenai pembagian kerja antara laki-laki dan perempuan dalam kehidupan kerja dan keluarga. Dalam pandangan tradisional masyarakat, peran laki-laki adalah sebagai kepala rumah tangga. Peran ini meletakkan tanggung jawab atas pencarian nafkah bagi keluarga pada laki-laki. Perempuan mendapatkan peran sebagai pengurus rumah tangga, sebuah peran yang menekankan tanggung jawab pada manajemen rumah tangga dan perawatan anak (Booth and Amato 1994); (Wiersma 1990). Dampak dari adanya pembagian peran seperti ini, ketika perempuan juga bekerja mencari nafkah bagi keluarga, masyarakat tetap menuntut perempuan untuk terus melakukan perannya secara penuh sebagai pengurus rumah tangga. Jadi, penambahan peran pada perempuan untuk bekerja mencari nafkah di luar rumah tidak diikuti dengan pembagian peran yang setara dalam pengurusan rumah tangga (Duxbury and Higgins 1991). Sebagai seorang yang profesional, perempuan diminta memberikan komitmen yang tinggi pada pekerjaan mereka "seperti lakilaki", sementara pada saat yang bersamaan mereka juga diminta memprioritaskan peran keluarga (Duxbury and Higgins 1991). Hal inilah yang kemudian menimbulkan beban ganda pada perempuan.

Beban ganda yang dipikul perempuan dapat memberi dampak yang kurang baik, baik pada kehidupan kerja maupun pada kehidupan keluarga. Tuntutan keluarga yang berlebihan bisa menghambat pemenuhan tuntutan kerja, atau sebaliknya, padatnya jadwal serta tuntutan kerja bisa menyulitkan perempuan dalam memenuhi tuntutan keluarga (Gutek, Searle, and Klepa 1991). Akibatnya, perempuan mengalami Konflik Pekerjaan Keluarga. Laki-laki tidak mengalami konflik pekerjaan-keluarga setinggi perempuan, mengingat tugas-tugas rumah yang diembannya relatif lebih sedikit (Wiersma 1990); (Kuswanti, H.D. dan Probosari 2008). 
Menurut Schultz (Schultz 2009), bagi beberapa individu, konflik muncul karena adanya ketidaksesuaian tanggung jawab antar peran dan terbatasnya sumber daya seperti waktu/energi. Individu yang memiliki sumber daya yang lebih banyak (atau mungkin lebih penting dan lebih tepat) mungkin akan lebih efektif menangani interaksi peran majemuk dalam kehidupan, sehingga muncul konstruk pengayaan peran majemuk. Dengan demikian peran pekerjaan dan keluarga tidak selalu bertentangan antara satu dengan lainnya dan mungkin memberikan pengaruh positif dengan berbagai cara.

Interaksi positif pekerjaan-keluarga menggambarkan aspek-aspek dari hubungan peran pekerjaan-keluarga yang dapat memengaruhi kehidupan pribadi, keluarga dan outcome yang berhubungan dengan pekerjaan dan keluarga. Pemahaman yang baik tentang tingkat interaksi positif pekerjaankeluarga akan dapat membantu organisasi mengembangkan strategi atau inisiatif untuk membantu karyawan secara efektif mengelola peran pekerjaan dan keluarga yang pada gilirannya akan menjamin komitmen karyawan dan kinerja yang lebih baik.

Untuk meningkatkan interaksi positif peran pekerjaan-keluarga tersebut perlu mengeksplorasi anteseden yang relevan. Greenhaus and Beutell (Jeffrey H. Greenhaus and Beutell 1985) menyarankan untuk menyelidiki berbagai sumber dukungan. Warner and Hausdorf (Warner and Hausdorf 2009) dan Wayne, (Wayne 2009) merekomendasikan anteseden dari pendekatan psikologis untuk memahami aspek-aspek positif dari beragam peran. Sementara Seng et al. (Seng, ASK. 2009) lebih spesifik menyebutkan perlunya dukungan religiusitas dalam pengelolaan interaksi pekerjaan-keluarga. Dalam penelitian ini, pendekatan psikologis yang digunakan sebagai anteseden interaksi peran dalam pekerjaan dan keluarga adalah kecerdasan spiritual.

Kecerdasan spiritual menunjukkan sekumpulan pengetahuan, keterampilan dan sikap yang menyebabkan terhubungnya kemampuan seseorang untuk memperoleh makna dan tujuan dalam pekerjaan dan hidup 
(Singh 2004). Kecerdasan spiritual memungkinkan orang untuk menyatukan hal-hal yang bersifat intrapersonal dan interpersonal, serta menjembatani kesenjangan antara diri sendiri dan orang lain (Hosaini et al. 2010). Dengan kata lain, kecerdasan spiritual berkontribusi dalam membantu memperbaiki hubungan dalam keluarga, teman dan kolega (Vaughan 2002).

Selain kecerdasan spiritual, pada abad ke-21 ini, koneksi antara kondisi psikologis karyawan dengan pekerjaannya memegang peranan yang sangat penting khususnya pada sektor pekerjaan yang berhubungan dengan informasi dan pelayanan (A.B Bakker 2009).

Perusahaan tidak lagi hanya mencari calon karyawan yang memiliki kemampuan di atas rata-rata, namun mereka juga mencari calon karyawan yang mampu menginvestasikan diri mereka sendiri untuk terlibat dalam pekerjaan, proaktif, dan memiliki komitmen tinggi terhadap standar kualitas kinerja (Arnold B. Bakker and Demerouti 2007). Lebih lanjut Bakker dan Leiter (Bakker Arnold B. 2010) menambahkan bahwa perusahaan juga membutuhkan karyawan yang engage dengan pekerjaannya.

Karyawan yang engage memiliki tingkat energi yang tinggi, antusias terhadap pekerjaan mereka, dan mereka sering merasa tenggelam dalam pekerjaannya sehingga waktu terasa cepat berlalu (Macey and Schneider 2008); (May, Gilson, and Harter 2004). Bordon dan Motowidlo (Bordon 1997) juga berpendapat bahwa karyawan yang engage tidak hanya melakukan aktivitas yang merupakan bagian dari tugasnya, tetapi ia juga melakukan aktivitas yang dapat memajukan organisasi. Oleh karena itu, work engagement ditandai dengan tingkat energi yang tinggi dan identifikasi yang kuat dengan pekerjaan seseorang (Arnold B. Bakker and Demerouti 2007).

Potret inilah yang menyebabkan kajian mengenai kualitas kehidupan kerja pada wanita pekerja menjadi suatu hal yang menarik yang mendorong penelitian ini untuk melakukan studi mengenai kualitas kehidupan kerja pada wanita pekerja di lingkungan Bank BRI Syariah Cabang Semarang. 
Kualitas Kehidupan Kerja pada Wanita Pekerja...

\section{Landasan Teori}

\section{Kualitas Kehidupan Kerja}

Kualitas kehidupan kerja atau Quality of Work Life (QWL) merupakan salah satu bentuk fisafat yang diterapkan manajemen dalam mengelola organisasi pada umumnya dan sumber daya manusia pada khususnya. Sebagai filsafat, kualitas kehidupan kerja merupakan cara pandang manajemen tentang manusia, pekerja dan organisasi. Unsur-unsur pokok dalam filsafat tersebut ialah kepedulian manajemen tentang dampak pekerjaan pada manusia, efektifitas organisasi serta pentingnya para karyawan dalam pemecahan keputusan terutama yang menyangkut pekerjaan, karier, penghasilan, dan nasib mereka dalam pekerjaan.

Ada dua pandangan mengenai maksud dari kualitas kehidupan kerja. Di satu sisi dikatakan bahwa kualitas kehidupan kerja adalah sejumlah keadaan dan praktik dari tujuan organisasi (seperti perkayaan kerja, penyeliaan yang demokratis, keterlibatan pekerja dan kondisi kerja yang nyaman). Sementara pandangan yang lain menyatakan bahwa kualitas kehidupan kerja adalah persepsi-persepsi karyawan bahwa mereka ingin merasa aman, secara relatif merasa puas, dan mendapat kesempatan mampu untuk tumbuh dan berkembang sebagai layaknya manusia (Cascio 1992).

Sedangkan Siagian dalam Arifin (Arifin 1999) menyatakan bahwa Quality of Work Life (QWL) sebagai filsafat manajemen menekankan:

1. Quality of Work Life (QWL) merupakan program yang kompetitif dan mempertimbangkan berbagai kebutuhan dan tuntutan karyawan.

2. Quality of Work Life (QWL) memperhitungkan tuntutan peraturan perundang-undangan seperti ketentuan yang mengatur tindakan yang diskriminan, perlakuan pekerjaan dengan cara-cara yang manusiawi, dan ketentuan tentang system imbalan upah minimum. 
3. Quality of Work Life (QWL) mengakui keberadaan serikat pekerja dalam organisasi dan berbagai perannya memperjuangkan kepentingan para pekerja termasuk dalam hal upah dan gaji, keselamatan kerja dan penyelesaian pertikaian perburuhan berdasarkan berbagai ketentuan normatif dan berlaku di suatu wilayah negara tertentu.

4. Quality of Work Life (QWL) menekankan pentingnya manajemen yang manusiawi, yang pada hakekatnya berarti penampilan gaya manajemen yang demokratik termasuk penyeliaan yang simpatik.

5. Dalam peningkatan Quality of Work Life (QWL), perkayaan pekerjaan merupakan bagian integral yang penting.

6. Quality of Work Life (QWL) mencakup pengertian tentang pentingnya tanggung jawab sosial dari pihak manajemen dan perlakuan manajemen terhadap para karyawan yang dapat dipertanggungjawabkan secara etis.

Pengertian kualitas kehidupan kerja menurut Koonts, Harold, dan Heinz (Koonts 1990), adalah suatu pendekatan sistem untuk mendesain pekerjaan (job design) dan pengembangan dalam ruang lingkup yang luas, terutama dalam melakukan job enrichment. Pendekatan ini dikombinasikan dengan pendekatan sistem sosioetnik dalam manajemen. Dengan demikian kualitas kehidupan kerja yang luas terhadap job enrichment, tetapi juga merupakan bidang multi disiplin dan merupakan perpaduan antara disiplin ilmu industri dan psikologi, teknik industri, teori organisasi, motivasi, leadership, dan industrial relation.

Konsep kualitas kehidupan kerja mengungkapkan pentingnya penghargaan terhadap manusia dalam lingkungan kerjanya. Dengan demikian peran penting dari kualitas kehidupan kerja adalah mengubah iklim organisasi agar secara teknis dan manusiawi membawa kepada kualitas kehidupan kerja yang lebih baik (Luthans 1995). Kualitas kehidupan kerja merumuskan bahwa setiap proses kebijakan yang diputuskan oleh 
perusahaan merupakan sebuah respon atas apa yang menjadi keinginan dan harapan karyawan mereka, hal itu diwujudkan dengan berbagi persoalan dan menyatukan pandangan mereka (perusahaan dan karyawan) ke dalam tujuan yang sama yaitu peningkatan kinerja karyawan dan perusahaan.

Menurut Lee dan Yudith (Ozley 1992), bahwa kualitas kehidupan kerja telah memberikan harapan terhadap kepuasan pekerja mengenai kebutuhan-kebutuhan personel melalui pengkayaan pengalaman dalam organisasi. Filosofi dasar dari konsep tersebut adalah peningkatan kualitas kehidupan kerja berasal dari semua effort pada setiap level/tingkatan organisasi untuk mendapatkan human dignity (sesuatu yang sangat bernilai) dan growth (pertumbuhan).

\section{Pengaruh Kecerdasan Spiritual terhadap Interaksi Positif Peran Pekerjaan-Keluarga}

Spiritual di tempat kerja merupakan istilah yang menggambarkan pengalaman karyawan yang bergairah dan berenergi dengan pekerjaan mereka, menemukan makna dan tujuan dalam pekerjaan mereka, merasa bahwa mereka dapat mengekspresikan diri dalam menyelesaikan pekerjaan, dan merasa terhubung dengan orang-orang yang bekerjasama dengan mereka (Kinjerski and Skrypnek 2004). Istilah ini juga menurut Kinjerski and Skripnek (Kinjerski and Skrypnek 2004), digunakan untuk menggambarkan sebuah budaya organisasi yang mendorong otonomi, kepercayaan, kebersamaan, dukungan, pengakuan, inovasi dan keadilan melalui kepemimpinan dan proses kerja. Salah satu cara mengintegrasikan spiritualitas di tempat kerja melalui sistem nilai-nilai suci/utama yang memungkinkan jiwa manusia untuk tumbuh dan berkembang (Butts 1999).

Kecerdasan spiritual yang tinggi ditandai dengan adanya pertumbuhan dan transformasi pada diri seseorang, tercapainya kehidupan yang berimbang atau bahkan memperkaya antara pekerjaan dan keluarga, serta 
adanya perasaan suka cita serta puas yang diwujudkan dalam bentuk menghasilkan kontribusi positif dan berbagi kebahagian kepada lingkungan.

H1: Kecerdasan spiritual berpengaruh positif terhadap interaksi positif peran pekerjaan-keluarga

\section{Pengaruh Work Engagement terhadap Interaksi Positif Peran Pekerjaan-Keluarga}

Pekerja wanita yang terikat (engaged) dengan pekerjaannya akan menurunkan kinerjanya pada peran di keluarga, dikarenakan tidak semua orang dapat memenuhi ekspektasinya terhadap peran pekerjaan dan peran yang lain diluar pekerjaan yang dapat memunculkan ketidakseimbangan pada peran keluarga, dalam hal ini pekerjaan memengaruhi keluarga (work interference family).

Kebermaknaan kerja dan keluarga didefinisikan Greenhaus dan Powel (J. H. Greenhaus and Powell 2006) sebagai sejauh mana pengalaman atau keterlibatan dalam suatu peran meningkatkan kualitas hidup dan memengaruhi peran yang lainnya. Kebermaknaan kerja-keluarga merupakan konstruk yang merepresentasikan bagaimana keluarga dan pekerjaan saling memberi manfaat. Kebermaknaan kerja-keluarga didasari atas pemikiran fundamental bahwa pekerjaan dan keluarga masing-masing memberikan individu dengan sejumlah sumber daya maupun manfaat lain yang dapat membantu individu untuk melakukan seluruh domain kehidupan lainnya lebih baik lagi (Barnett and Hyde 2001). Kebermaknaan kerjakeluarga terjadi ketika sumber-sumber yang terjadi pada suatu peran meningkatkan kinerja peran yang lain.

H2: Work engagement berpengaruh positif terhadap interaksi positif peran pekerjaan-keluarga 


\section{Pengaruh Interaksi Positif Peran Pekerjaan-Keluarga terhadap Kualitas Kehidupan Kerja}

Istilah terkini interaksi positif pekerjaan-keluarga adalah work-family enrichment yang digunakan oleh Greenhaus and Powell (J. H. Greenhaus and Powell 2006). Keduanya mendefinisikan work-family enrichment sebagai sejauh mana pengalaman dalam satu peran meningkatkan kualitas hidup dalam peran lain. Pengertian yang sama diberikan oleh Carlson et al. (Carlson, Grzywacz, and Michele Kacmar 2010) dan Greenhaus and Powell (J. H. Greenhaus and Powell 2006) yang menyatakan tingkat dimana aktivitas dalam satu domain meningkatkan aktivitas dalam domain lainnya. Warner and Hausdorf (Warner and Hausdorf 2009) mengajukan model work-family enrichment yang didasarkan pada penelitian-penelitian sebelumnya tentang peningkatan peran, fasilitasi pekerjaan-keluarga, limpahan positif, teori ekspasionis, dan work-family enrichment yang mendukung gagasan bahwa peran ganda domain pekerjaan dan keluarga dapat bermanfaat bagi kesehatan mental, kesehatan fisik dan kinerja serta dapat mengurangi pengaruh negatif potensial dari peran lain.

H3: interaksi positif peran pekerjaan-keluarga berpengaruh positif terhadap kualitas kehidupan kerja

\section{Metode Penelitian}

\section{Populasi dan Sampel}

Populasi dan sampel yang digunakan dalam penelitian ini dilakukan dengan pendekatan judgement sampling dimana penarikan sampel dilakukan berdasarkan karakteristik yang ditetapkan terhadap elemen populasi target yang disesuaikan dengan tujuan atau masalah penelitian, yaitu:

1. Responden adalah pegawai wanita yang berada di lingkungan Bank BRI Syariah Cabang Semarang, 
2. Telah berkeluarga dan memiliki anak.

Mengacu pada kriteria yang telah ditetapkan tersebut, maka jumlah responden yang digunakan dalam penelitian ini adalah sebanyak 101 responden.

\section{Jenis dan Sumber Data}

Data yang diperlukan dalam penelitian ini, diperoleh melalui sumber primer, yaitu mengacu pada informasi yang diperoleh dari tangan pertama oleh peneliti yang berkaitan dengan variabel minat untuk tujuan spesifik penelitian. Data primer yang diperoleh dalam penelitian ini adalah data tentang persepsi responden terhadap variabel kecerdasan spiritual, work engagement, interaksi positif peran pekerjaan-keluarga dan kualitas kehidupan kerja.

\section{Metode Pengumpulan Data}

Pengumpulan data dilakukan melalui wawancara dengan menggunakan kuesioner. Tipe pertanyaan dalam kuesioner adalah pertanyaan tertutup dimana responden diminta untuk membuat pilihan diantara serangkaian alternatif yang diberikan oleh peneliti (Sekaran 2003) pada skala 1-7.

\section{Definisi Operasional dan Indikator Variabel Penelitian}

\section{Variabel Kecerdasan Spiritual}

Instrumen pengukuran kecerdasan spiritual diukur dengan menggunakan daily spiritual experiences scale (DSES) dari Underwood (Underwood 2003), yaitu:

a. Saya merasakan kehadiran Tuhan

b. Pengalaman hidup saya saling terkoneksi

c. Selama ibadah, atau di saat lain saat berhubungan dengan Tuhan, saya merasakan sukacita, yang mengangkat saya dari keprihatinan saya sehari-hari 
d. Saya menemukan kekuatan dalam agama atau spiritualitas saya

e. Saya menemukan kenyamanan dalam agama atau spiritualitas saya

f. Saya merasa dalam kedamaian batin atau harmoni

g. Saya meminta pertolongan Tuhan di tengah aktivitas sehari-hari

h. Saya merasakan kasih Tuhan untuk saya secara langsung

i. Saya merasakan cinta Tuhan melalui orang lain

j. Saya secara spiritual tersentuh oleh keindahan ciptaan

k. Saya merasa bersyukur

l. Saya merasa tidak mementingkan diri sendiri terhadap orang lain

m. Saya menerima orang lain bahkan ketika mereka melakukan halhal yang menurut saya salah

n. Saya ingin lebih dekat kepada Tuhan atau bersatu dengan Dia.

\section{Variabel Work Engagement}

Pengukuran variabel work engagement diadopsi dari penelitian Ariana \& Riana (Ariana 2016) yang meliputi:
a. Adanya harapan yang besar terhadap pekerjaan
b. Adanya keterlibatan emosional terhadap pekerjaan
c. Adanya rasa tanggung jawab terhadap pekerjaan
d. Adanya rasa bangga terhadap pekerjaan
e. Adanya keinginan untuk mobilitas ke atas

\section{Variabel Interaksi Positif Peran Pekerjaan-Keluarga}

Pengukuran variabel interaksi positif peran pekerjaan-keluarga Diadopsi dari penelitian Ariana \& Riana (Ariana 2016) yang meliputi:
a. Kurang bahkan tidak adanya waktu untuk keluarga
b. Tidak ada waktu untuk kehidupan bermasyarakat
c. Penggunaan hari libur untuk bekerja 
d. Permasalahan dalam keluarga memengaruhi waktu untuk bekerja

e. Permasalahan dalam keluarga memengaruhi produktivitas dalam bekerja

f. Tuntutan pekerjaan memengaruhi kehidupan keluarga

g. Terjadi keluhan dari anggota keluarga akibat dari pekerjaan

h. Keluarga merasa tidak mendapat dukungan dari peran sebagai ibu rumah tangga dan seorang istri

i. $\quad$ Sering merasa lelah setelah pulang bekerja

\section{Variabel Kualitas Kehidupan Kerja}

Indikator yang digunakan untuk mengukur variabel kualitas kehidupan kerja dikembangkan dari penelitian Yusuf (Yusuf 2011) yang meliputi:

a. Partisipasi dalam organisasi

b. Lingkungan kerja yang kondusif

c. Perhatian pada masalah kesejahteraan ekonomi

d. Pengembangan potensi diri

e. Penghargaan terhadap karyawan

Adapun teknik analisis data yang digunakan untuk menguji model dan hipotesis penelitian dilakukan dengan pendekatan Structural Equation Modeling (SEM).

\section{Analisis Data}

Adapun hasil penguji model penelitian dengan menggunakan SEM diuraikan di bawah ini. 
Gambar 1. Hasil Pengujian Model Penelitian

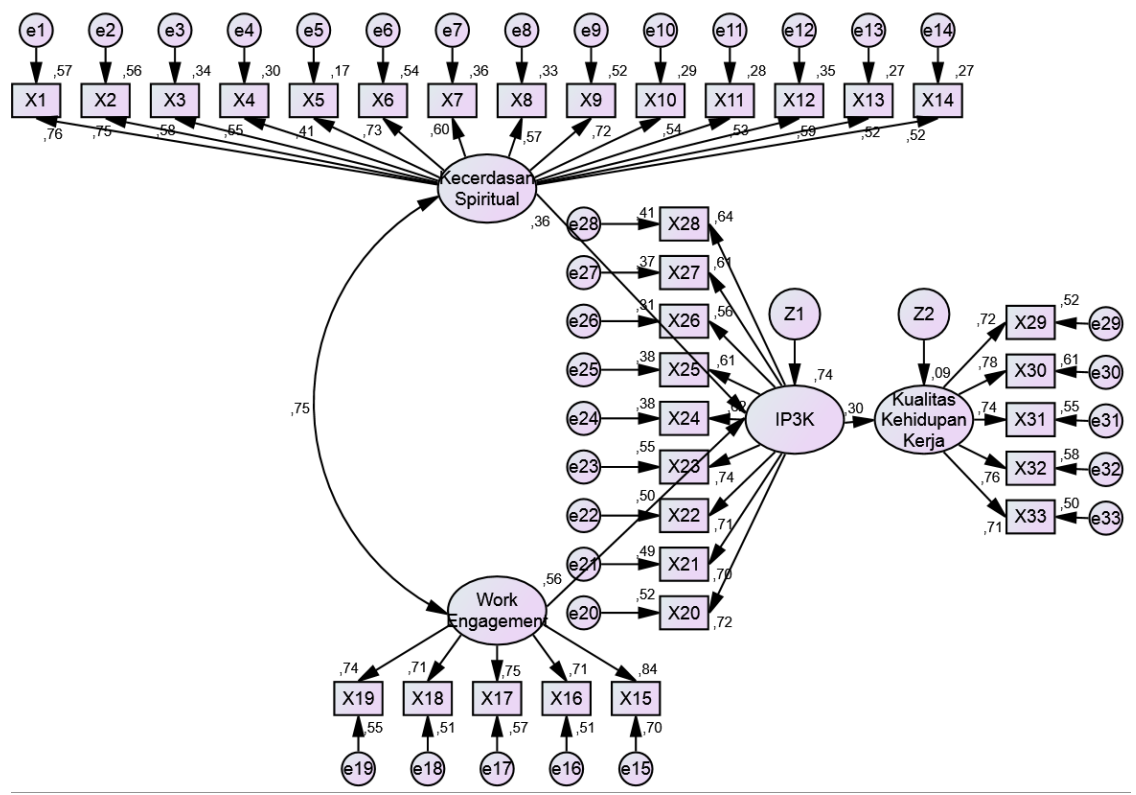

Sumber: Data primer yang diolah, 2017

\section{Analisis Konfirmatori}

Disebut sebagai teknik analisis confirmatory factor karena pada tahap ini model akan mengkonfirmasi apakah indikator yang diamati dapat mencerminkan faktor yang dianalisis. Terdapat uji dasar dalam confirmatory factor analysis yaitu uji signifikansi bobot factor. Uji signifikansi bobot factor dilakukan untuk menguji apakah sebuah indikator dapat digunakan untuk mengkonfirmasi bahwa indikator itu dapat bersama-sama dengan indikator lainnya menjelaskan sebuah variabel laten. Pengujian ini dilakukan dengan menggunakan dua tahapan analisis, yaitu analisis terhadap nilai standardized regression weight dan analisis bobot factor (Ferdinand 2006): 
Zuhdan Ady Fataron

\section{a. Standardized Regression Weight}

Nilai lambda yang dipersyaratkan adalah harus mencapai $\geq 0,700$ (Ferdinand 2006), bila nilai lambda atau factor loading lebih rendah dari 0,700 dipandang variabel itu tidak berdimensi sama dengan variabel lainnya untuk menjelaskan sebuah variabel laten.

Tabel 1. Nilai Regression Weight Indikator Variabel Penelitian

\begin{tabular}{|c|c|c|c|c|c|c|c|}
\hline & & & $\begin{array}{r}\text { Std } \\
\text { Estimate }\end{array}$ & Estimate & S.E. & C.R. & $\mathbf{P}$ \\
\hline $\mathrm{X} 1$ & $<--$ & Kecerdasan_Spiritual & ,758 & 1,000 & & & \\
\hline $\mathrm{X} 2$ & $<--$ & Kecerdasan_Spiritual & ,750 & 1,014 & 131 & 7,736 & $* * *$ \\
\hline $\mathrm{X3}$ & $<--$ & Kecerdasan_Spiritual & ,581 & 949 & 165 & 5,750 & $* * *$ \\
\hline $\mathrm{X} 4$ & $<--$ & Kecerdasan_Spiritual & ,552 & 825 & 151 & 5,460 & $* * *$ \\
\hline X5 & $<--$ & Kecerdasan_Spiritual & ,411 & 608 & 152 & 4,011 & $* * *$ \\
\hline $\mathrm{x} 6$ & $<--$ & Kecerdasan_Spiritual & ,733 & 1,263 & 169 & 7,484 & $* * *$ \\
\hline $\mathrm{X} 7$ & $<--$ & Kecerdasan_Spiritual & 604 & ,954 & 158 & 6,027 & $* * *$ \\
\hline $\mathrm{X} 8$ & $<--$ & Kecerdasan_Spiritual & ,571 & 863 & 154 & 5,614 & $* * *$ \\
\hline X9 & $<--$ & Kecerdasan_Spiritual & 721 & 962 & 132 & 7,302 & $* * *$ \\
\hline $\mathrm{X} 10$ & $<--$ & Kecerdasan_Spiritual & ,540 & 824 & 156 & 5,290 & $* * *$ \\
\hline $\mathrm{X} 11$ & $<--$ & Kecerdasan_Spiritual & ,526 & ,725 & 141 & 5,141 & $* * *$ \\
\hline $\mathrm{X} 12$ & $<--$ & Kecerdasan_Spiritual & ,590 & 900 & 157 & 5,735 & $* * *$ \\
\hline $\mathrm{X} 13$ & $<--$ & Kecerdasan_Spiritual & ,521 & 798 & 157 & 5,089 & $* * *$ \\
\hline $\mathrm{X} 14$ & $<--$ & Kecerdasan_Spiritual & ,524 & 733 & 144 & 5,090 & $* * *$ \\
\hline $\mathrm{X} 15$ & $<--$ & Work_Engagement & ,837 & 1,000 & & & \\
\hline $\mathrm{X} 16$ & $<--$ & Work_Engagement & 714 & 878 & 113 & 7,790 & $* * *$ \\
\hline $\mathrm{X} 17$ & $<--$ & Work_Engagement & ,752 & 954 & 113 & 8,427 & $* * *$ \\
\hline $\mathrm{X} 18$ & $<--$ & Work_Engagement & 714 & 925 & 117 & 7,893 & $* * *$ \\
\hline $\mathrm{X} 19$ & $<--$ & Work_Engagement & ,742 & 1,057 & 129 & 8,203 & $* * *$ \\
\hline $\mathrm{X} 20$ & $<--$ & IP3K & ,718 & 1,000 & & & \\
\hline$X 21$ & $<--$ & IP3K & ,703 & 1,135 & 168 & 6,772 & $* * *$ \\
\hline $\mathrm{X} 22$ & $<--$ & IP3K & 710 & 1,015 & 148 & 6,851 & $* * *$ \\
\hline $\mathrm{X} 23$ & $<--$ & IP3K & ,743 & 991 - & 139 & 7,114 & $* * *$ \\
\hline $\mathrm{X} 24$ & $<--$ & IP3K & 617 & 922 & 157 & 5,872 & $* * *$ \\
\hline $\mathrm{X} 25$ & $<--$ & IP3K & 613 & 872 & 153 & 5,694 & $* * *$ \\
\hline X26 & $<---$ & IP3K & ,558 & 736 & 143 & 5,150 & $* * *$ \\
\hline
\end{tabular}


Kualitas Kehidupan Kerja pada Wanita Pekerja...

\begin{tabular}{llrrrrc}
\hline & & $\begin{array}{r}\text { Std } \\
\text { Estimate }\end{array}$ & Estimate & S.E. & C.R. & P \\
\hline X27 <--- & IP3K &, 607 &, 891 &, 155 & 5,747 & $* * *$ \\
X28 <--- & IP3K &, 643 &, 971 &, 161 & 6,035 & $* * *$ \\
X29 <--- & Kualitas_Kehidupan_Kerja &, 720 & 1,000 & & & \\
X30 <--- & Kualitas_Kehidupan_Kerja &, 783 &, 938 &, 133 & 7,064 & $* * *$ \\
X31 <--- & Kualitas_Kehidupan_Kerja &, 742 &, 759 &, 110 & 6,873 & $* * *$ \\
X32 <--- & Kualitas_Kehidupan_Kerja &, 764 &, 902 &, 131 & 6,890 & $* * *$ \\
X33 <--- & Kualitas_Kehidupan_Kerja &, 708 &, 943 &, 145 & 6,508 & $* * *$ \\
\hline
\end{tabular}

Sumber: Data primer yang diolah, 2017

Berdasarkan hasil pengujian yang disajikan dalam Tabel 1 terlihat bahwa masih terdapat indikator-indikator yang digunakan untuk mengukur variabel penelitian memiliki nilai standardized regression weight yang lebih rendah dari 0,700. Sehingga dapat disimpulkan bahwa indikator tersebut secara bersama-sama menyajikan unidimensionalitas untuk variabel latennya.

\section{b. Bobot Faktor}

Bobot faktor menunjukkan kuatnya dimensi-dimensi itu membentuk faktor latennya. Bobot faktor dapat dianalisis dengan menggunakan uji-t yang dalam analisis SEM uji-t identik dengan nilai Critical Ratio (CR).

Berdasarkan hasil yang disajikan dalam Tabel 1 tampak bahwa masingmasing indikator memiliki nilai CR $>1,960$ (berdasarkan nilai statistik t pada $\alpha=5 \%$ ) dan tingkat signifikansi $<0.05$. Hal ini menunjukkan bahwa indikator-indikator tersebut secara signifikan merupakan dimensi dari faktor laten yang dibentuk.

Meskipun nilai CR dan signifikansi memenuhi persyaratan, namun masih terdapat nilai lambda atau factor loading yang di bawah 0,700 . Oleh sebab itu, indikator-indikator yang memiliki nilai lambda atau factor loading yang di bawah 0,700 tidak diikutsertakan dalam pengujian model selanjutnya.

Economica: Jurnal Ekonomi Islam - Volume 8, Nomor 2 (2017) 


\section{Analisis Full Model}

Pengujian model penelitian dilakukan dengan menggunakan indikatorindikator pengukuran variabel penelitian yang memiliki nilai lambda atau factor loading di atas 0,700. Adapun hasil-hasil pengujian pada kedua tahap tersebut diuraikan di bawah ini.

Gambar 2. Hasil Pengujian Model Penelitian Direvisi

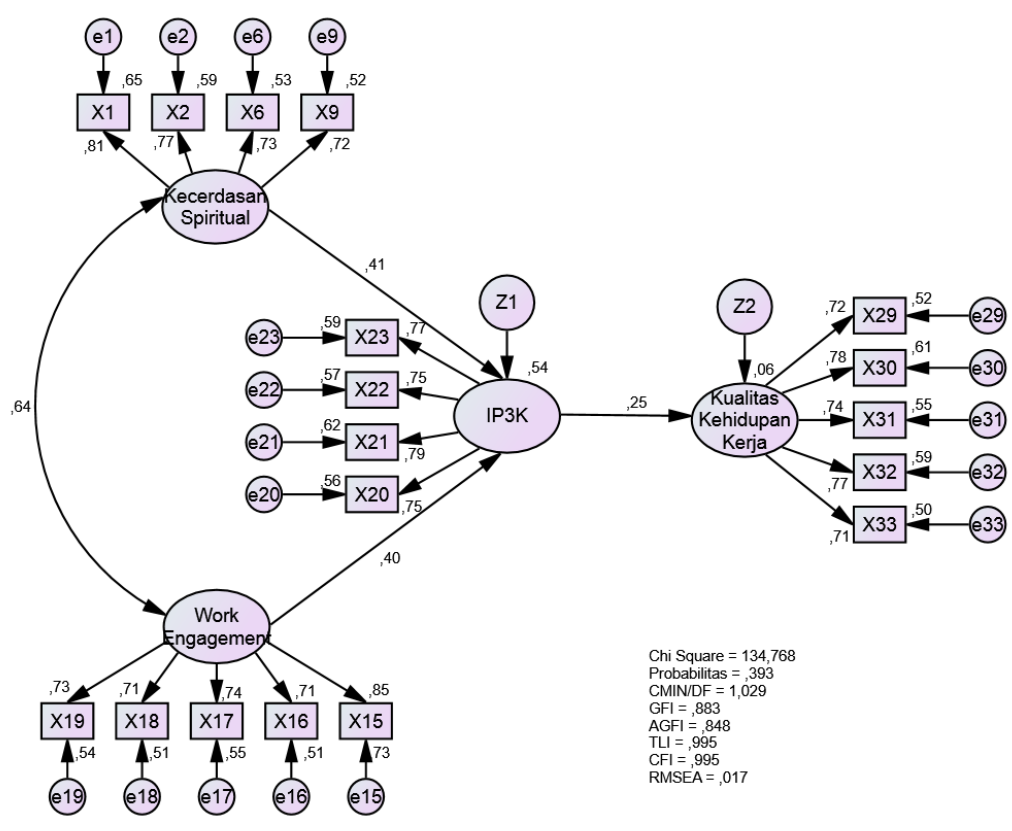

Sumber: Data Primer yang Diolah, 2017

\section{a. Uji Kesesuaian Model - Goodness of Fit Test}

Tahap pertama pengujian ditujukan untuk melihat kesesuaian model. Hasil pengujian kesesuaian model yang dikembangkan dalam penelitian ini disajikan dalam Tabel 2 di bawah ini. 
Tabel 2. Hasil Pengujian Kelayakan Full Model

\begin{tabular}{rccc}
\hline Goodness of Fit Indeks & Cut off Value & Hasil & Evaluasi Model \\
\hline Chi-Square (df = 131) & $\leq 158,712$ & 134,768 & Baik \\
Probability & $\geq 0,05$ & 0,393 & Baik \\
CMIN/DF & $\leq 2,00$ & 1,029 & Baik \\
GFI & $\geq 0,90$ & 0,883 & Marginal \\
AGFI & $\geq 0,90$ & 0,848 & Marginal \\
TLI & $\geq 0,95$ & 0,995 & Baik \\
CFI & $\geq 0,95$ & 0,995 & Baik \\
RMSEA & $\leq 0,08$ & 0,015 & Baik
\end{tabular}

Sumber: Data primer yang diolah, 2017

Berdasarkan hasil yang disajikan dalam Tabel 2 terlihat bahwa nilai $C h i$ Square $=134,768$ dengan probabilitas $=0,393$ dan nilai-nilai indeks yang meliputi CMIN/DF $(1,029)$, TLI $(0,995)$, CFI $(0,995)$, dan RMSEA $(0,015)$, termasuk dalam kategori baik sehingga dapat disimpulkan bahwa tidak terdapat perbedaan antara matriks kovarians sampel dan matriks kovarians populasi yang diestimasi atau dengan kata lain model adalah fit.

\section{b. Uji Kausalitas}

Setelah melakukan penilaian terhadap asumsi-asumsi yang harus dipenuhi dalam menggunakan analisis dengan SEM, selanjutnya akan dilakukan pengujian hipotesis. Pengujian keempat hipotesis yang diajukan dalam penelitian ini dilakukan dengan menganalisis nilai Critical Ratio (CR). 
Tabel 3. Pengujian Hipotesis

\begin{tabular}{|c|c|c|c|c|c|c|c|}
\hline & & & $\begin{array}{c}\text { Std } \\
\text { Estimate }\end{array}$ & Estimate & S.E. & C.R. & $\mathbf{P}$ \\
\hline IP3K & $<---$ & $\begin{array}{l}\text { Kecerdasan_ } \\
\text { Spiritual }\end{array}$ & ,413 & ,416 & 142 & 2,923 & ,003 \\
\hline IP3K & $<---$ & $\begin{array}{l}\text { Work_} \\
\text { Engagement }\end{array}$ & ,400 & 372 & 128 & 2,908 & ,004 \\
\hline $\begin{array}{l}\text { Kualitas_ } \\
\text { Kehidupan_Kerja }\end{array}$ & $<---$ & IP3K & 250 & 192 & ,090 & 2,123 & ,034 \\
\hline
\end{tabular}

Sumber: Data primer yang diolah, 2017

Parameter estimasi untuk pengujian pengaruh kecerdasan spiritual terhadap interaksi positif peran pekerjaan-keluarga menunjukkan nilai CR sebesar 2,923 dengan probabilitas sebesar 0,003 . Oleh karena nilai $C R$ $(2,923)>2,00$ dan nilai probabilitas $(0,003)<0,05$ maka dapat disimpulkan bahwa variabel kecerdasan spiritual berpengaruh signifikan positif terhadap interaksi positif peran pekerjaan-keluarga.

Parameter estimasi untuk pengujian pengaruh work engagement terhadap interaksi positif peran pekerjaan-keluarga menunjukkan nilai CR sebesar 2,908 dengan probabilitas sebesar 0,004 . Oleh karena nilai CR $(2,90)$ $>2,00$ dan nilai probabilitas $(0,004)<0,05$ maka dapat disimpulkan bahwa variabel work engagement berpengaruh signifikan positif terhadap interaksi positif peran pekerjaan-keluarga.

Parameter estimasi untuk pengujian pengaruh interaksi positif peran pekerjaan-keluarga terhadap kualitas kehidupan kerja menunjukkan nilai CR sebesar 2,123 dengan probabilitas sebesar 0,034. Oleh karena nilai CR $(2,123)>2,00$ dan nilai probabilitas $(0,034)<0,05$ maka dapat disimpulkan bahwa variabel interaksi positif peran pekerjaan-keluarga berpengaruh signifikan positif terhadap kualitas kehidupan kerja. 
Kualitas Kehidupan Kerja pada Wanita Pekerja...

\section{Simpulan}

Penelitian ini ditujukan untuk membuktikan secara empiris mengenai variabel yang dapat menjelaskan kualitas kehidupan kerja. Terdapat tiga hal yang dapat disimpulkan dari hasil penelitian ini, yaitu:

1. Pengujian yang dilakukan pada variabel kecerdasan spiritual dan interaksi positif peran pekerjaan-keluarga menunjukkan bahwa kecerdasan spiritual terbukti berpengaruh signifikan positif terhadap interaksi positif peran pekerjaan-keluarga.

2. Pengujian yang dilakukan pada variabel work engagement dan interaksi positif peran pekerjaan-keluarga menunjukkan bahwa work engagement terbukti berpengaruh signifikan positif terhadap interaksi positif peran pekerjaan-keluarga.

3. Pengujian yang dilakukan pada variabel interaksi positif peran pekerjaan-keluarga dan kualitas kehidupan kerja menunjukkan bahwa interaksi positif peran pekerjaan-keluarga terbukti berpengaruh signifikan positif terhadap kualitas kehidupan kerja.

Studi ini telah membuktikan bahwa untuk memperkuat kehidupan kerja yang berkualitas diperlukan interaksi positif peran pekerjaan-keluarga. Interaksi peran pekerjaan-keluarga perlu didukung oleh kecerdasan spiritual dan work engagement yang kuat. Merujuk pada temuan tersebut, maka saran yang diajukan adalah sebagai berikut:

1. Saya merasakan kehadiran Tuhan, pengalaman hidup saya saling terkoneksi, saya merasa dalam kedamaian batin atau harmoni, saya merasakan cinta Tuhan melalui orang lain, adalah hal-hal yang perlu diperkuat untuk meningkatkan kecerdasan spiritual.

2. Adanya harapan yang besar terhadap pekerjaan, adanya keterlibatan emosional terhadap pekerjaan, adanya rasa tanggung jawab terhadap pekerjaan, adanya rasa bangga terhadap pekerjaan, dan adanya keinginan untuk mobilitas ke atas merupakan wujud work engagement.

Economica: Jurnal Ekonomi Islam - Volume 8, Nomor 2 (2017) 


\section{Daftar Pustaka}

Ariana, I Wayan Jendra and I. Gede Riana. 2016. "Pengaruh Work-Family Conflict, Keterlibatan Kerja dan Stress Kerja terhadap Kepuasan Kerja Karyawan." E-Jurnal Manajemen Universitas Udayana 5 (7): 4630-59.

Arifin, Noor. 1999. "Aplikasi Konsep Quality of Work Life Dalam Upaya Menumbuhkan Motivasi Karyawan Berkinerja Unggul." Usahawan 10: 25-29.

Bakker, A.B. 2009. "Building Engagement in the Workplace." In The Peak Performing Organization, edited by R. J. Burke \& C.L. Cooper, 50-72. UK: Routledge.

Bakker, Arnold B., and Evangelia Demerouti. 2007. "The Job DemandsResources Model: State of the Art." Journal of Managerial Psychology 22 (3): 309-28. https://doi.org/10.1108/02683940710733115.

Bakker Arnold B., dan Michael P Leiter. 2010. Work Engagement: A Handbook of Essential Theory and Research. New York: Psychology Press.

Barnett, R C, and J S Hyde. 2001. "Women, Men, Work, and Family. An Expansionist Theory." The American Psychologist 56 (10): 781-96. http://www.ncbi.nlm.nih.gov/pubmed/11675985.

Booth, Alan, and Paul R. Amato. 1994. "Parental Gender Role Nontraditionalism and Offspring Outcomes." Journal of Marriage and the Family 56 (4). National Council on Family Relations: 865. https://doi.org/10.2307/353599.

Bordon, W.C and S.J Motowidlo. 1997. Human Performance: Organizational Citizenship Behavior and Contextual Behavior. New Jersey: Lawrence Erlbaum Associates.

Butts, Dan. 1999. "Spirituality at Work: An Overview." Journal of Organizational Change Management 12 (4): 328-32. https://doi.org/ 10.1108/09534819910282162.

Carlson, Dawn S., Joseph G. Grzywacz, and K. Michele Kacmar. 2010. "The Relationship of Schedule Flexibility and Outcomes via the Work-family Interface." Journal of Managerial Psychology 25 (4): 330-55. https://doi.org/10.1108/02683941011035278.

Cascio, Wayne F. 1992. Managing Human Resource: Productivity, Qualitty of Work Life. New York: McGraw Hill. 
Duxbury, Linda E., and Christopher A. Higgins. 1991. "Gender Differences in Work-Family Conflict." Journal of Applied Psychology 76 (1): 60-74. https://doi.org/10.1037/0021-9010.76.1.60.

Ferdinand, Augusty. 2006. Structural Equation Modeling Dalam Penelitian Manajemen. Semarang: Badan Penerbit Universitas Diponegoro.

Greenhaus, J. H., and G. N. Powell. 2006. "When Work and Family Are Allies: A Theory of Work-Family Enrichment." Academy of Management Review 31 (1). Academy of Management: 72-92. https://doi.org/10.5465/ AMR.2006.19379625.

Greenhaus, Jeffrey H., and Nicholas J. Beutell. 1985. "Sources of Conflict between Work and Family Roles." The Academy of Management Review 10 (1). Academy of Management: 76. https://doi.org/10.2307/258214.

Gutek, Barbara A., Sabrina Searle, and Lilian Klepa. 1991. "Rational versus Gender Role Explanations for Work-Family Conflict." Journal of Applied Psychology 76 (4): 560-68. https://doi.org/10.1037/00219010.76.4.560.

Hosaini, Maryam, Habibah Elias, Steven Eric Krauss, and Siti Aishah. 2010. "A Review Study on Spiritual Intelligence, Adolescence and Spiritual Intelligence, Factors That May Contribute to Individual Differences in Spiritual Intelligence, and the Related Theories." International Journal of Psychological Studies 2 (2). https://doi.org/10.5539/ijps.v2n2p179.

Kinjerski, Val M., and Berna J. Skrypnek. 2004. "Defining Spirit at Work: Finding Common Ground." Journal of Organizational Change Management 17 (1): 26-42. https://doi.org/10.1108/ 09534810410511288.

Koonts, Harold dan Weinrich Heinz. 1990. Manajemen. Jakarta: Erlangga.

Kuswanti, H.D. dan Probosari, N. 2008. “Peran Dukungan Organisasional Dan Dukungan Suami Dalam Memoderasi Tuntutan Waktu Peran Kerja Terhadap Konflik Peran Ganda." Jurnal Manajemen \& Bisnis Utilitas 16 (1): 15-25.

Luthans, Fred. 1995. Organizational Behaviour. 8th editio. California: McGraw Hill.

Macey, William H., and Benjamin Schneider. 2008. "The Meaning of Employee Engagement." Industrial and Organizational Psychology 1 (1). 
Cambridge University Press: 3-30. https://doi.org/10.1111/j.17549434.2007.0002.x.

May, Douglas R., Richard L. Gilson, and Lynn M. Harter. 2004. "The Psychological Conditions of Meaningfulness, Safety and Availability and the Engagement of the Human Spirit at Work." Journal of Occupational and Organizational Psychology 77 (1). Blackwell Publishing Ltd: 11-37. https://doi.org/10.1348/096317904322915892.

Ozley, Lee M. and Yudith S. Ball. 1992. "Quality of Work Life: Initiating Success Full Effort in Labor Management Organization." Jurnal Personnel Administrator, no. 27 May 1982.

Schultz, Lisa A. 2009. "Exploring the Relationship between the Positive and Negative Sides of the Work-Family Interface: The Role of Enrichment in Buffering the Effects of Time-, Strain-, and Behavior-Based Conflict." Disertation. Indiana, Purdue University.

Sekaran, Uma. 2003. Research Methods For Business: A Skill Building Aproach. New York-USA: John Wiley and Sons, Inc.

Seng, ASK., SB. Bujang and R. Ahmad. 2009. "Work-Family Interface: The Relationship between Work-Family and Religious Support and Its Influence on Job, Family and Life Satisfaction." Paper Submitted to BAI 2009 International Conference on Business \& Information. Kuala Lumpur, 6-8 July.

Singh, T and R.K Premarajan. 2004. "A Scale to Measure Spiritual Competence." In Conference Paper in Proceedings Asia Academic of Management Conference Shanghai. Sanghai, December 18.

Underwood, LG. 2003. Daily Spiritual Experiences, In Multidimensional Measurement of Religiousness/Spirituality for Use in Health Research: A Report of the Fetzer Insitute/National Insitute on Aging Working Group.

Vaughan, Frances. 2002. “What Is Spiritual Intelligence?" Journal of Humanistic Psychology 42 (2). Sage PublicationsSage CA: Thousand Oaks, CA: 16-33. https://doi.org/10.1177/0022167802422003.

Warner, Melissa A., and Peter A. Hausdorf. 2009. "The Positive Interaction of Work and Family Roles." Journal of Managerial Psychology 24 (4): 37285. https://doi.org/10.1108/02683940910952732. 
Wayne, J.H. 2009. "Reducing Conceptual Confusion: Clarifying the 'Positive' Side of Work and Family." Paper Presented at the Annual Conference for the Society of Industrial/Organizational Psychologist.

Wiersma, Uco J. 1990. "Gender Differences in Job Attribute Preferences: Work-Home Role Conflict and Job Level as Mediating Variables." Journal of Occupational Psychology 63 (3). Blackwell Publishing Ltd: 231-43. https://doi.org/10.1111/j.2044-8325.1990.tb00524.x.

Yusuf, Tamzil. 2011. "Pengaruh Kualitas Kehidupan Kerja, Komitmen Karyawan, Dan Motivasi Kerja Terhadap Kepuasan Kerja Karyawan PDAM Balikpapan." 2011. https://mafiadoc.com/pengaruh-kualitaskehidupan-kerja-blog-ekonomi_5a2665e61723ddc2f2ac2afa.html. 
